\title{
Comprehensive Benefits Evaluation of Land Use in the Shuonan Mining Area Based on Triangle Model
}

\author{
Cui Yixin*, Zhang Ru, Li Yongfeng \\ Email address: \\ 270774651@qq.com (Cui Yixin), zhangru1993cumt@163.com (Zhang Ru) \\ ${ }^{*}$ Corresponding author
}

School of Environment Science and Spatial Informatics, China University of Mining and Technology, Xuzhou, China

To cite this article:

Cui Yixin, Zhang Ru, Li Yongfeng. Comprehensive benefits Evaluation of Land Use in the Shuonan Mining Area Based on Triangle Model. International Journal of Environmental Monitoring and Analysis. Vol. 5, No. 5, 2017, pp. 143-149. doi: 10.11648/j.ijema.20170505.15

Received: June 8, 2017; Accepted: June 20, 2017; Published: November 20, 2017

\begin{abstract}
As a carrier of all things, land resources are very limited, the contradiction between human and land has become one of the focus of human survival and development. In the coal mining area, the land occupation and subsidence caused by the exploitation of coal resources continue to aggravate the contradiction between the economic benefit, social benefit and ecological benefit of land use, which directly affects the sustainability of land use. Based on the full utilization of the land resources in the mining area and improvement of land use benefit in the coal mining area, the economic, social and ecological benefits of land use in the coal mining area were analyzed comprehensively, and the comprehensive benefits evaluation index system of land use in coal mining area was built, then the weights of the evaluation indexes were determined by entropy method. According to the quantitative analysis of land use benefit in coal mining area, the triangle model was used to evaluate the comprehensive benefits of land use in mining area from 2005 to 2014. Through division of land use benefit types in coal mining area, the three trends of benefit are analyzed, and the inherent factors of land use efficiency fluctuation in coal mining area are revealed, which provides the basis for strengthening the sustainable land use in coal mining area.
\end{abstract}

Keywords: Mining Area, Land Use Benefit, Triangle Model

\section{Introduction}

Land use benefit is the sum of the economic, ecological and social benefits brought about by the arrangement and use of land quantity and quality in space and time. [1] Its essence is material outputs or effective results achieved by the land investment and consumption per unit area in social, economic, ecological and environmental aspects of regional development. [2]

At present, the research on land use benefit is mainly concentrated in urban land, a small amount of research area in the development zone or village, and the evaluation of land use benefit in coal mining area is rarely involved. However, according to statistics, $90 \%$ of coal resources in China are distributed in the dry and semi-dry climate zones of the mainland where soil erosion and land desertification are very serious, the vegetation coverage is low and the ecological environment is fragile. And in these places, land is the most direct performance of coal resource exploitation.
The change of land use type caused by land damage will directly affect the growth of surface crops and the grain yield of cultivated land, which will inevitably affect the land use benefit.

\section{Evaluation Index System of Comprehensive Benefits of Land Use in Coal Mining Area}

\subsection{Factors of Land Use Benefit in Coal Mining Area}

The exploitation of coal resources brings the rise of coal mining area. The change of land use type and structure will significantly affect the income distribution, the education status of the residents, the employment rate, the ecological conditions of the land and the quality of the environment, which ultimately affect the comprehensive benefits of land use. 


\subsubsection{Factors of Economic Benefit of Land Use}

The impacts on the economic benefit of land use is mainly from two aspects: input and output. The land economic outputs are produced by a number of inputs (capital, land, etc.). [3] From the aspect of land safeguard, mining land is the fundamental guarantee to determine the land use benefit, therefore, reasonable allocation among construction land, agricultural land and unused land is conducive to improving the economic benefit of land use. In addition, in construction land, output value and the profits of enterprises will be affected by investment in fixed assets, and in agricultural land, investment in fixed assets will also affect the efficiency of farmers, thus affecting the grain output and income. From the aspect of output, coal production and grain production is the direct performance of land use economic benefit, especially in the production period, coal production and sales increase rapidly, enterprise and government have allocated the proceeds of mine production, of which specific performance is the increase in corporate profits and government revenue. Residents indirectly allocated proceeds, mainly due to coal enterprises led the development of the service industry.

\subsubsection{Factors of Social Benefit of Land Use}

Land use social benefit is the social impact of land use results, mainly performed in the social development and living standards. From the aspect of social development situation, the population and its changes will increase the pressure of land space allocation and put forward higher requirements of the land productivity [4]. And traffic is the link between coal mining area and the city, affecting the output of agricultural products and coal products. From the aspect of residential living standard, because the coal mining area is suburbs far away from the of the city, the land type is mostly coal industrial land and cultivated land, the income and consumption of local residents is the most direct reflection on social benefit.

\subsubsection{Factors of Ecological Benefit of Land Use}

The ecological benefit of land use in coal mining area are different from cities, because the anthropomorphic disturbances of coal land are more intense, and its ecological benefit are mainly affected by ecological conditions and environmental quality. Ecological conditions is the status of land use in coal mining areas, besides forest land, water and the entire mining area landscape will directly reflect the ecological benefit of land use, subsidence is the main benefit of ecological factors, it is also main characteristics of the land; the quality of the environment, that is, land damage caused by coal resources exploitation and cultivation, which is mainly reflected in impacts on mining environment in the process of land use, these factors are often negative, such as the "three wastes" in the process of coal mining, the application of chemical fertilizers during cultivation, which all are man-made damage leading the incoordination between ecological benefit and socio-economic benefit.

\subsection{Evaluation Index System of Comprehensive Benefits of Land Use in Coal Mining Area}

Based on the analysis of factors of land use benefit, combined with the characteristics of coal mining area, the comprehensive benefits evaluation index system of land use in coal mining area is constructed according to the principles of scientificity, operability, representation and independence. (Table 1)

Table 1. Evaluation index system of comprehensive benefits of land use in coal mining area.

\begin{tabular}{|c|c|c|c|c|}
\hline Target layer & Criteria layer & Factor layer & Index layer & Correlation \\
\hline \multirow{19}{*}{$\begin{array}{l}\text { Evaluation } \\
\text { Index System } \\
\text { of } \\
\text { Comprehensive } \\
\text { benefits of } \\
\text { Land Use in } \\
\text { Coal Mining } \\
\text { Area A }\end{array}$} & \multirow{6}{*}{ Economic benefit $\mathrm{B}_{1}$} & \multirow{3}{*}{ Land Guarantee $\mathrm{C}_{1}$} & Per capita construction land $\mathrm{D}_{1}$ & Positive \\
\hline & & & Per capita cultivated land $\mathrm{D}_{2}$ & Positive \\
\hline & & & fixed assets investment per unit area $\mathrm{D}_{3}$ & Positive \\
\hline & & \multirow{3}{*}{ Production capacity $\mathrm{C}_{2}$} & Coal outputs per unit $\operatorname{areaD}_{4}$ & Positive \\
\hline & & & Grain yield per unit area $\mathrm{D}_{5}$ & Positive \\
\hline & & & Fiscal revenue per unit area $D_{6}$ & Positive \\
\hline & \multirow{6}{*}{ Social benefit $\mathrm{B}_{2}$} & \multirow{4}{*}{ Social Development $\mathrm{C}_{3}$} & Population load per unit area $\mathrm{D}_{8}$ & Positive \\
\hline & & & Population natural growth rate $\mathrm{D}_{9}$ & Positive \\
\hline & & & Highway density $\mathrm{D}_{10}$ & Positive \\
\hline & & & Engel coefficient $\mathrm{D}_{11}$ & Positive \\
\hline & & \multirow[t]{2}{*}{ Living standard $\mathrm{C}_{4}$} & Per capita income $\mathrm{D}_{12}$ & Positive \\
\hline & & & Retail sales of consumer goods per capita $D_{13}$ & Positive \\
\hline & \multirow{7}{*}{ Ecological benefit $\mathrm{B}_{3}$} & \multirow{4}{*}{ Ecological condition $\mathrm{C}_{5}$} & The proportion of forest land to total land area $D_{14}$ & Positive \\
\hline & & & The proportion of subsidence to the total land area $D_{16}$ & Negative \\
\hline & & & The proportion of land occupation to the total land area $D_{17}$ & Negative \\
\hline & & & COD emissions per unit area $\mathrm{D}_{18}$ & Negative \\
\hline & & \multirow{3}{*}{ Environmental quality $\mathrm{C}_{6}$} & $\mathrm{SO}_{2}$ emissions per unit area $\mathrm{D}_{19}$ & Negative \\
\hline & & & Emission of coal gangue per unit area $\mathrm{D}_{20}$ & Negative \\
\hline & & & Fertilizer application per unit area $\mathrm{D}_{21}$ & Negative \\
\hline
\end{tabular}




\section{Evaluation Model and Evaluation Criteria}

\subsection{Evaluation Model and Method}

\subsubsection{Data Normalization}

As the selected indicators of different sources, their units and magnitudes are not the same, for a comparison between indicators, the indicators need to be standardized.

Positive indicator:

$$
x_{\mathrm{P}}=\left(x_{i}-x_{\min }\right) /\left(x_{\max }-x_{\min }\right)
$$

Negative indicator:

$$
x_{\mathrm{N}}=\left(x_{\max }-x_{i}\right) /\left(x_{\max }-x_{\min }\right)
$$

\subsubsection{Determine the Weight of the Evaluation Index}

Entropy method, analytic hierarchy process, Delphi method and coefficient of variation method are commonly used to determine the weight, relatively more mature. AHP and Delphi method are subjective method, which has certain subjectivity. There is little research on the land use benefit evaluation in coal mining area, and there is no reference. The subjectivity leads to the increase of error. And the entropy method and the coefficient of variation coefficient are all objective weighting methods, among them, the coefficient of variation is more suitable for the fuzzy evaluation of the evaluation target, and this method is not enough to pay attention to the economic significance of the indicators, and is clearly not suitable for benefit evaluation. Therefore, the entropy method is the final choice.

The index entropy $\left(e_{i}\right)$ is expressed as:

$$
\begin{gathered}
\mathrm{e}_{\mathrm{i}}=-\mathrm{k} \sum \mathrm{p}_{\mathrm{im}} \ln \left(\mathrm{p}_{\mathrm{im}}\right), \mathrm{k}=1 / \ln (\mathrm{n}) \\
p_{i t}=x_{i t} / \sum_{i=1}^{n} x_{i t}
\end{gathered}
$$

$p_{i t}$ : it represents the proportion of the indicator value of the item(t)under item(i).

Finally, define the weight value $\left(w_{i}\right)$ :

$$
w_{i}=g_{i} / \sum_{i=1}^{m} g_{i}, \quad g_{i}=1-e_{i}
$$

$\mathrm{m}$ : it represents $(\mathrm{m})$ indicators.

\subsubsection{Calculate the Comprehensive Index Value}

After calculating the standard value and weight of each index, the economic, social and ecological benefits of land use in coal mining area can be calculated by formulas.

$$
\mathrm{I}=\sum_{1}^{m} w_{i} X_{i}
$$

\subsubsection{Triangle Model}

The land use benefit of coal mining area is closely related to the mine life cycle, and the socio-economic benefit are closely related to the ecological benefits. Therefore, selecting the triangle model to evaluate the comprehensive benefits of land use can objectively classify the dominant benefit types of land use in the coal mining area, which can as a way to improve the land use benefit of coal mining area.

The three sides of the equilateral triangle are $\mathrm{X}$-axis, $\mathrm{Y}$-axis and Z-axis, which represent the ratio of economic benefit $\left(\mathrm{I}_{\mathrm{J}}\right)$, social benefit $\left(\mathrm{I}_{\mathrm{S}}\right)$ and ecological benefit $\left(\mathrm{I}_{\mathrm{E}}\right)$ to comprehensive benefits $\left(\mathrm{I}_{\mathrm{T}}\right)$. every axis will be divided into five sections: very low $(0-0.2)$, general $(0.2-0.4)$, relatively high (0.4-0.6), higher (0.6-0.8); very high (0.8-1), thus forming 25 regions in the interior of the triangle, 25 types. The ratio of land use benefit to comprehensive benefits determines the type of land use benefit in coal mining area during the study period. In addition, according to the counterclockwise direction, the triangle can be divided into six areas at intervals of $60^{\circ}$ to reflect the trend of benefit change. [5] (Figure 1)

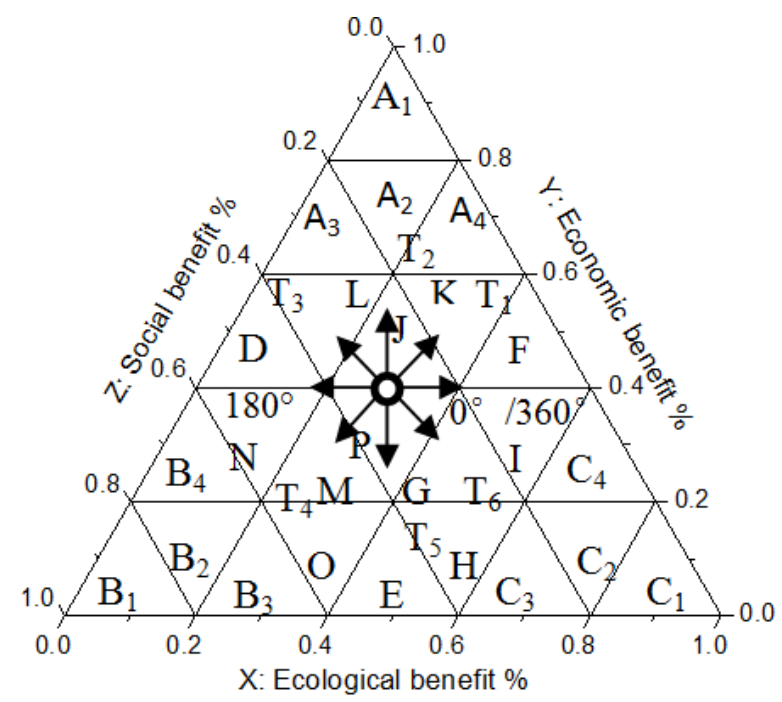

Figure 1. Triangle model of land use benefit in mining area.

\subsection{Evaluation Criteria}

According to the $\mathrm{r} 25$ types of land use benefit and 6 trends,

\begin{tabular}{|c|c|c|c|c|c|}
\hline \multirow{2}{*}{ Area } & \multicolumn{3}{|l|}{ Range } & \multicolumn{2}{|c|}{ Type of land use benefit } \\
\hline & $\mathbf{I}_{\mathbf{E}}$ & $\mathbf{I}_{\mathbf{J}}$ & $\mathbf{I}_{\mathbf{S}}$ & Feature & Relationship \\
\hline $\mathrm{A}_{1}$ & $0 \sim 0.2$ & $0.8 \sim 1$ & $0 \sim 0.2$ & Economic lead type & \\
\hline $\mathrm{B}_{1}$ & $0 \sim 0.2$ & $0 \sim 0.2$ & $0.8 \sim 1$ & Social lead type & Serious imbalance \\
\hline $\mathrm{C}_{1}$ & $0.8 \sim 1$ & $0 \sim 0.2$ & $0 \sim 0.2$ & Ecological lead type & \\
\hline $\mathrm{A}_{2}$ & $0 \sim 0.2$ & $0.6 \sim 0.8$ & $0 \sim 0.2$ & Economic lead type & Imbalance \\
\hline
\end{tabular}
this paper determines the evaluation criteria of land use benefit in coal mining area and relative change trend of land use economic benefit, social benefit and ecological benefit during the study period. [5] (Table 2 and Table 3)

Table 2. Evaluation criteria for land use benefit types based on triangle model. 


\begin{tabular}{|c|c|c|c|c|c|}
\hline \multirow{2}{*}{ Area } & \multicolumn{3}{|l|}{ Range } & \multicolumn{2}{|l|}{ Type of land use benefit } \\
\hline & $\mathbf{I}_{\mathbf{E}}$ & $\mathbf{I}_{\mathbf{J}}$ & $\mathbf{I}_{\mathbf{S}}$ & Feature & Relationship \\
\hline $\mathrm{B}_{2}$ & $0 \sim 0.2$ & $0 \sim 0.2$ & $0.6 \sim 0.8$ & Social lead type & \\
\hline $\mathrm{C}_{2}$ & $0.6 \sim 0.8$ & $0 \sim 0.2$ & $0 \sim 0.2$ & Ecological lead type & \\
\hline $\mathrm{A}_{3}$ & $0 \sim 0.2$ & $0.6 \sim 0.8$ & $0.2 \sim 0.4$ & Economic lead, ecological lag type & \\
\hline $\mathrm{A}_{4}$ & $0.2 \sim 0.4$ & $0.6 \sim 0.8$ & $0 \sim 0.2$ & Economic lead, social lag type & \\
\hline $\mathrm{B}_{3}$ & $0.2 \sim 0.4$ & $0 \sim 0.2$ & $0.6 \sim 0.8$ & Social lead, economic lag type & On the verge of \\
\hline $\mathrm{B}_{4}$ & $0 \sim 0.2$ & $0.2 \sim 0.4$ & $0.6 \sim 0.8$ & Social lead, ecological lag type & imbalance \\
\hline $\mathrm{C}_{3}$ & $0.6 \sim 0.8$ & $0.2 \sim 0.4$ & $0 \sim 0.2$ & Ecological lead, social lag type & \\
\hline $\mathrm{C}_{4}$ & $0.6 \sim 0.8$ & $0 \sim 0.2$ & $0.2 \sim 0.4$ & Ecological lead, economic lag type & \\
\hline $\mathrm{K}$ & $0.2 \sim 0.4$ & $0.4 \sim 0.6$ & $0 \sim 0.2$ & Economic lead, social lag type & \\
\hline $\mathrm{L}$ & $0 \sim 0.2$ & $0.4 \sim 0.6$ & $0.2 \sim 0.4$ & Economic lea, ecological lag type & \\
\hline $\mathrm{N}$ & $0 \sim 0.2$ & $0.2 \sim 0.4$ & $0.4 \sim 0.6$ & Social lead, ecological lag & Junior \\
\hline $\mathrm{O}$ & $0.2 \sim 0.4$ & $0 \sim 0.2$ & $0.4 \sim 0.6$ & Social lead, economic lag type & coordination \\
\hline $\mathrm{H}$ & $0.4 \sim 0.6$ & $0 \sim 0.2$ & $0.2 \sim 0.4$ & Ecological lead, social lag type & \\
\hline I & $0.4 \sim 0.6$ & $0.2 \sim 0.4$ & $0 \sim 0.2$ & Ecological lead, economic lag type & \\
\hline E & $0.4 \sim 0.6$ & $0 \sim 0.2$ & $0.4 \sim 0.6$ & Economic lag type & \\
\hline $\mathrm{F}$ & $0.4 \sim 0.6$ & $0.4 \sim 0.6$ & $0 \sim 0.2$ & Social lag type & condination \\
\hline D & $0 \sim 0.2$ & $0.4 \sim 0.6$ & $0.4 \sim 0.6$ & Ecological lag type & coordination \\
\hline $\mathrm{J}$ & $0.2 \sim 0.4$ & $0.4 \sim 0.6$ & $0.2 \sim 0.4$ & Economic lead type & \\
\hline M & $0.2 \sim 0.4$ & $0.2 \sim 0.4$ & $0.4 \sim 0.6$ & Social lead type & Good coordination \\
\hline G & $0.4 \sim 0.6$ & $0.2 \sim 0.4$ & $0.2 \sim 0.4$ & Ecological lead type & \\
\hline $\mathrm{P}$ & $0.2 \sim 0.4$ & $0.2 \sim 0.4$ & $0.2 \sim 0.4$ & Coordinated development type & $\begin{array}{l}\text { Excellent } \\
\text { coordination }\end{array}$ \\
\hline
\end{tabular}

Table 3. Evaluation criteria of land use benefit change trend in coal mining area based on triangle model.

\begin{tabular}{lllcl}
\hline \multirow{2}{*}{ Area } & \multirow{2}{*}{ Change range } & \multicolumn{3}{l}{ Performance and trend } \\
\cline { 3 - 5 } & & $\mathbf{I}_{\mathbf{E}}$ & $\mathbf{I}_{\mathbf{J}}$ & $\mathbf{I}_{\mathbf{S}}$ \\
\hline $\mathrm{T}_{1}$ & $0^{\circ} \sim 60^{\circ}$ & $\uparrow$ & $\uparrow$ & $\downarrow$ \\
$\mathrm{T}_{2}$ & $60^{\circ} \sim 120^{\circ}$ & $\downarrow$ & $\uparrow$ & $\downarrow$ \\
$\mathrm{T}_{3}$ & $120^{\circ} \sim 180^{\circ}$ & $\downarrow$ & $\uparrow$ & $\uparrow$ \\
$\mathrm{T}_{4}$ & $180^{\circ} \sim 240^{\circ}$ & $\downarrow$ & $\downarrow$ & $\uparrow$ \\
$\mathrm{T}_{5}$ & $240^{\circ} \sim 300^{\circ}$ & $\uparrow$ & $\downarrow$ & $\uparrow$ \\
$\mathrm{T}_{6}$ & $300^{\circ} \sim 360^{\circ}$ & $\uparrow$ & $\downarrow$ & $\downarrow$ \\
\hline
\end{tabular}

\section{Results of Evaluation in the Shuonan Mining Area}

\subsection{The Study Area}

Shuonan mining area is located in Shuozhou City, Shanxi, east longitude $112^{\circ} 15^{\prime}-112^{\circ} 34^{\prime}$, north latitude $39^{\circ} 07^{\prime} 39^{\circ} 25^{\prime}$, mining area is $580 \mathrm{~km}^{2}$. It belongs to arid and semi-arid area and has four distinct seasons, and its ecology is fragile. The entire mining area includes Maying Fort, Fengyu, Gaozhuang, Fanwang Temple and Majialiang 5 mine and a Zhangjiazui reconnaissance area.

\subsection{Data Processing and Weight Determination}

In this paper, the coal production and socio-economic data of the Shuonan mining area are obtained through the statistical yearbook of Shuozhou City in Shouzhou City from 2005 to 2014, and the land use data are obtained mainly through the present situation of land use in the Shuonan mining areas. According to estimation, per million tons of coal cause 0.27 -hectare subsidence and 0.005 -hectare land occupation. [6] According to this, the subsidence area and occupation area can be estimated. On the basis of the basic data, the index value is calculated by the relevant calculation, the index value is standardized, and the weight is obtained by the entropy method. (Table 4)

Table 4. Standardization value and weight of land use benefit index in coal mine area.

\begin{tabular}{|c|c|c|c|c|c|c|c|c|c|c|c|}
\hline Index & 2005 & 2006 & 2007 & 2008 & 2009 & 2010 & 2011 & 2012 & 2013 & 2014 & Weight \\
\hline $\mathrm{D}_{1}$ & 1 & 0.9729 & 0.9355 & 0.4393 & 0.8777 & 0.3921 & 0.3008 & 0 & 0.3353 & 0.4566 & 0.04975 \\
\hline $\mathrm{D}_{2}$ & 1 & 0.9729 & 0.9355 & 0.4393 & 0.8777 & 0.3921 & 0.3008 & 0 & 0.3353 & 0.4566 & 0.04975 \\
\hline $\mathrm{D}_{3}$ & 0 & 0.0207 & 0.0853 & 0.2289 & 0.4314 & 0.5889 & 0.5870 & 0.7036 & 1 & 0.5398 & 0.04987 \\
\hline $\mathrm{D}_{4}$ & 0 & 0.0226 & 0.0461 & 0.1871 & 0.2589 & 0.4949 & 0.7664 & 0.9333 & 1 & 0.7699 & 0.05046 \\
\hline $\mathrm{D}_{5}$ & 0 & 0.0355 & 0.2189 & 0.2659 & 0.2660 & 0.4914 & 0.4914 & 0.7796 & 0.8578 & 1 & 0.04996 \\
\hline $\mathrm{D}_{6}$ & 0 & 0.0249 & 0.1150 & 0.2448 & 0.3264 & 0.4400 & 0.6853 & 0.8536 & 1 & 0.8826 & 0.05022 \\
\hline $\mathrm{D}_{7}$ & 0.3394 & 0.0071 & 0.2319 & 0 & 0.9811 & 0.9364 & 0.8532 & 0.9681 & 1 & 0.9997 & 0.05048 \\
\hline $\mathrm{D}_{9}$ & 1 & 0.8359 & 0.5385 & 0.4667 & 0.2410 & 0.1179 & 0 & 0.2000 & 0.3846 & 0.2974 & 0.04970 \\
\hline $\mathrm{D}_{10}$ & 0 & 0.4312 & 0.6393 & 0.7110 & 0.7073 & 0.7978 & 0.8883 & 0.9493 & 0.9655 & 1 & 0.04931 \\
\hline $\mathrm{D}_{11}$ & 0 & 0.1119 & 0.3132 & 0.8355 & 0.5827 & 0.7297 & 0.6772 & 1 & 0.8913 & 0.5639 & 0.04968 \\
\hline $\mathrm{D}_{12}$ & 0 & 0.0480 & 0.2260 & 0.2766 & 0.3846 & 0.5079 & 0.6995 & 0.8617 & 0.8545 & 1 & 0.04999 \\
\hline$D_{13}$ & 0 & 0.0436 & 0.1205 & 0.1886 & 0.3398 & 0.3297 & 0.4108 & 0.4498 & 0.8051 & 1 & 0.04985 \\
\hline $\mathrm{D}_{14}$ & 1 & 0.9729 & 0.9355 & 0.4393 & 0.8777 & 0.3921 & 0.3008 & 0 & 0.3353 & 0.4566 & 0.04975 \\
\hline $\mathrm{D}_{15}$ & 1 & 0.9729 & 0.9355 & 0.4393 & 0.8777 & 0.3921 & 0.3008 & 0 & 0.3353 & 0.4566 & 0.04975 \\
\hline $\mathrm{D}_{17}$ & 1 & 0.9774 & 0.9539 & 0.8129 & 0.7411 & 0.5051 & 0.2336 & 0.0667 & 0 & 0.2301 & 0.05023 \\
\hline
\end{tabular}




\begin{tabular}{llllllllllll}
\hline Index & $\mathbf{2 0 0 5}$ & $\mathbf{2 0 0 6}$ & $\mathbf{2 0 0 7}$ & $\mathbf{2 0 0 8}$ & $\mathbf{2 0 0 9}$ & $\mathbf{2 0 1 0}$ & $\mathbf{2 0 1 1}$ & $\mathbf{2 0 1 2}$ & $\mathbf{2 0 1 3}$ & $\mathbf{2 0 1 4}$ & Weight \\
\hline $\mathrm{D}_{18}$ & 1 & 0.9124 & 0.8286 & 0.5921 & 0.4810 & 0.3597 & 0.1598 & 0.0714 & 0 & 0.0221 & 0.05032 \\
$\mathrm{D}_{19}$ & 1 & 0.9124 & 0.8286 & 0.5921 & 0.4810 & 0.3597 & 0.1598 & 0.0714 & 0 & 0.0221 & 0.05032 \\
$\mathrm{D}_{20}$ & 1.0000 & 0.9774 & 0.9539 & 0.8129 & 0.7411 & 0.5051 & 0.2336 & 0.0667 & 0 \\
$\mathrm{D}_{21}$ & 0.5030 & 0.4253 & 0.3475 & 0.3436 & 0 & 0.9692 & 0.2103 & 0.9459 & 0.9339 & 0.2301 & 0.05023 \\
\hline
\end{tabular}

\subsection{Evaluation Results}

On the basis of the weight, the economic benefit, social benefit, ecological benefit and comprehensive benefits of land use are calculated according to the index data of Table 4, and the triangle model was constructed by Origin software. (Figure 2)

In triangle figure, from the right to the left, the evaluation results of the comprehensive benefits of land use in the Shuonan mining area from 2005 to 2014 are represented as coordinate points. According to the calculation and evaluation criteria, the land use benefit from 2005-2014 in the Shuonan mining area is determined, and its sustainability is judged. (Table 5)

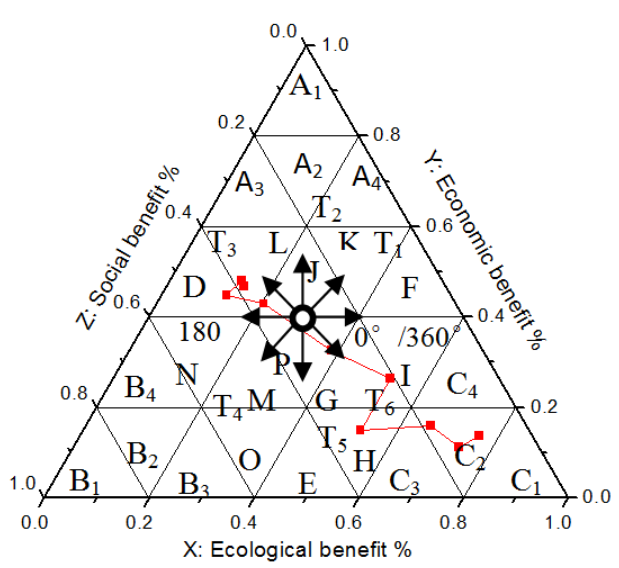

Figure 2. Comprehensive benefits evaluation of land use in the Shuonan mining area based on triangle model.

Table 5. Evaluation results of comprehensive benefits of land use in the Shuonan mining area.

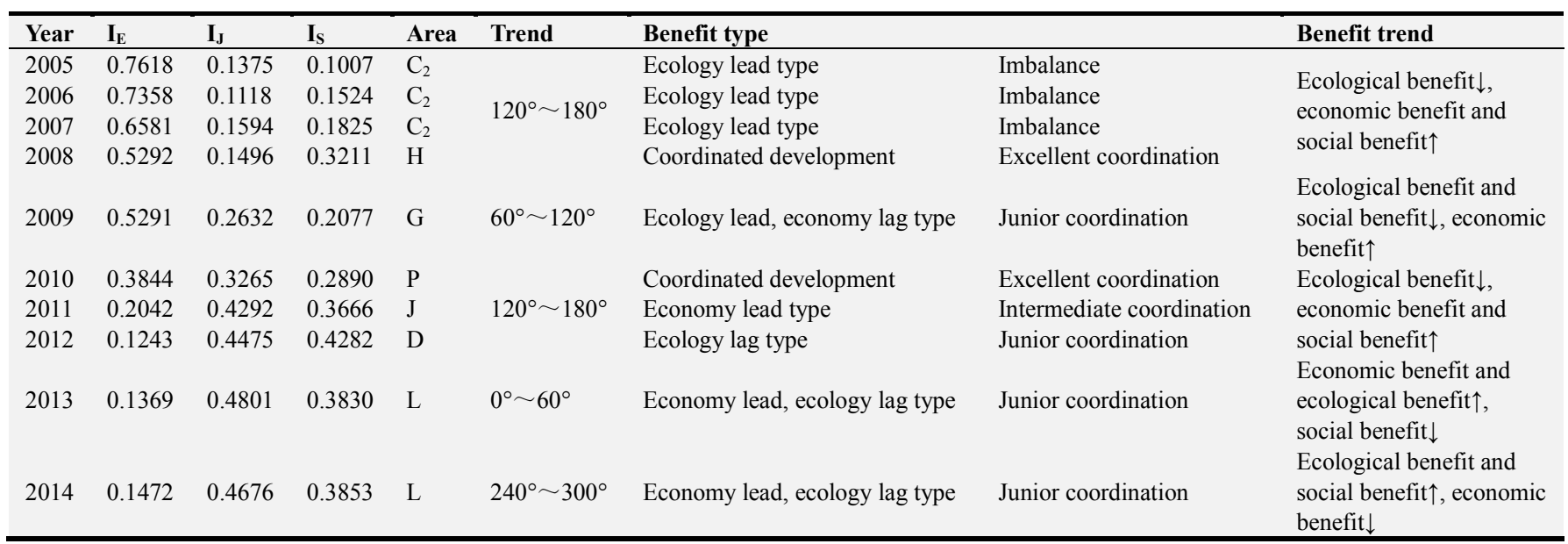

During the period from 2005 to 2009, the ecological benefit of land use in the mining area decreased, while its social and economic benefits increased. the Shuonan mining area was still at the early stage of coal resources mining, economy development mainly relied on agriculture, subsidence had not yet appeared on a large scale, the ecological environment of land was better. Therefore, at early period of this stage, the ecology led the overall benefit of land use in the entire mining area. With the increase of coal resource exploitation scale and mining intensity, the occupation and destruction of land were gradually emerging. The coal industry led to the economic development of the mining area and residents indirectly distributed the prohits of the coal enterprises, increasing economic benefit and social led to coordinate development between ecological benefit and them.

During the period from 2010 to 2012, the ecological benefits of land use in the mining area decreased, while its social and economic benefits increased. At this time, due to the construction and development of Majialiang mine, with the exploitation of coal resources, the whole mining area ushered in a huge economic prosperity, the living standards of the residents increased, on the whole, socio-economic benefits showed an upward trend, at the same time, land occupation and subsidence caused by coal enterprises gradually affected the cultivation. At this time the ecological benefit of land use of was affected negatively. Mining became into economic-oriented.

During the period from 2013 to 2014, the coal production in the Shuonan mining area decreased due to the impact that coal prices continued to slump and the ecology and environment disturbed by the damage to the land. The economic role of coal industry on the mining area weakened and the social benefit also declined, which would slow down damage to land.

In summary, during the study period, the land use benefit 
in coal mining area was affected by the coal resources exploitation, the land ecology has been seriously damaged, and gradually lose balance. With the socio-economic development, the type of land use benefit changed from coordination type, then to economy lead type, subsequently, incoordination among society benefit, economic benefit and ecological benefit gradually exacerbated. It can be seen that when the damage to the ecological environment of the land reaches a certain degree, the lag of the land ecology will break the pattern of the original type led by ecology, which conforms to the basic development law of the production stage of the mine life cycle.

\section{Conclusion and Suggestions}

\subsection{Conclusion}

According to the evaluation results of land use benefit in coal mining area, on the one hand, the triangle model objectively divides the benefit type of land use in coal mining area, determines the evaluation criteria reasonably through the relative proportion, and further reveals the inherent reason why land use benefit changes with development of coal mining area through the analysis of change trend. Compared with the traditional evaluation model and method, the triangle model can ensure the objectivity of the evaluation results, and can make a qualitative and quantitative reflection on the contradiction between the socio-economic development and the ecological development in the coal mining area.

On the other hand, the change of land use benefit in coal mining area is almost consistent with the mine life cycle law. With the increasing scale and intensity of coal resources exploitation, the economic benefit, social benefit and ecological benefit of land use in mining area will be characterized by cyclical change throughout the mining life cycle. The land use benefit in the Shuonan mining area was in uncoordinated unsustainable development stage led by economy, needing some measures to reduce the "three wastes" emissions, improve land use efficiency and implement land reclamation of ecological remediation. [7]

\subsection{Suggestion}

From the influencing factors, according to the index weight analysis, it was can be seen that the main factors affecting the economic, social and ecological benefits of land use respectively are proportion of the tertiary industry, per capita income, $\mathrm{COD}$ emissions per unit area and $\mathrm{SO}_{2}$ emissions per unit area. To improve the comprehensive benefits of land use, must be combined with its influencing factors. The quantity and quality of land resources in coal mining area, the main limiting factors of comprehensive benefits of land use in coal mining area and the influence degree of these factors must be found out to form a best structure of land use and achieve maximum of land use benefit. In addition, the coal mining area have a typical characteristic of mutual penetration among population, resources, economy and other factors [8], and the relationship between the three benefits in the process of land use is also related. Ensuring the coordination of economic benefit, social benefit and ecological benefit of land use in coal mining area is the main breakthrough to improve the comprehensive benefits of land use.

From the evolution of land use benefit, there are several sub-ecosystems in the coal mining area, and the land use of urban and industrial ecosystems such as forest land, grassland and farmland will lead to deterioration of the ecological storage in the whole system. The conversion from forest land, grassland and cultivated land and other ecosystem land to the town and industrial ecosystem land will lead to the storage deterioration of the ecological system in mining area. [9] Therefore, the eco-environmental protection investment of the land run through the entire mining area of the life cycle, but it is also necessary that develop different strategies for different stages. [10] For example, the Shuonan mining area is at production stage, with the increase of coal mining intensity and scale, the land use benefit is changed from the ecology lead type to the economy lead type, the contradiction between the socio-economic benefits and the ecological benefit of the land becomes more and more obvious. Therefore, at the early period of exploitation, it is essential to increase land investment and output per unit area for the economy development. when ecology lag emerges, improvement of environmental protection investment, timely land reclamation and ecological restoration, restoration of crop cultivation, vegetation cultivation are expected to implemented.

\section{Acknowledgements}

This paper is supported by the National Natural Science Foundation of China (Grant No. 51374208) and the National Key Research and Development Program, China (Grant No. 2016YFC0501109). The authors thank them for their effort.

\section{References}

[1] L Ganghui, W Cifang, "Study on the comparison of urban land use benefit," J. Political Geography, vol. 23, pp. 367-370, 2003.

[2] L Qiquan, Z Xin, G Xuesong, "Study on the coupled coordination pattern of land use degree and benefit in Hilly area, Sichuan," J. Journal of Agricultural Modernization, vol. 35, pp. 97-102, 2014.

[3] L Jia, "Minjuan. Evaluation of economic benefit of land use in Baoji City," J. Journal of Soil and Water Conservation, vol. 18 pp. 216-220, 2011.

[4] Z Shihai, C Shiyin, Z Fei, "Evaluation and optimization of social benefit of land use in Zhanjiang City," J. Guangdong Agricultural Sciences, vol. 11, pp. 43-46, 2008.

[5] S Xingxing, F Zhongjiang, L Yuntiang, "Evaluation of land use benefit based on triangle model in Zhengding County, Hebei," J. Journal of Soil and Water Conservation, vol. 32, pp. 206-210, 2012. 
[6] H Shujin, S Guangquan. "The development of mining industry and the forecast of damage to land," J. Resources Science, vol. 24, pp. 17-21, 2002.

[7] L Jia, L Guoping, C Mingzhe, "Study on sustainability evaluation of land use in mining cities based on triangle model," J. Journal of Soil and Water Conservation, vol. 19, pp. 196-201, 2012.

[8] W Hui, D Zhongyi, J Feifei, "Study on the coupling relationship between coal resources and land resources in coal mining area,” J. China Mining Industry, vol. 25, pp. 93-98, 2016.

[9] Z Xiaoran, B Zhongke, C Yingui, "Ecosystem evolution and ecological storage estimation of super large opencast coal mine," J. Acta Ecologica Sinica, vol. 36, pp. 5038-5048, 2016.

[10] Y Lixia, X Hao, Y Shaofeng, "Study on spatial difference of economic benefit of land use based on coupled coordination degree - taking Zhejiang as an example," J. China Land Science, pp. 83-88, 2015. 